\title{
A Novel Approach to Prevent Damage from Earthquakes and Tsunamis with the Utilization of a Proportional Surface Pyramidal Structure and Modified Underground Two-Part Hexagonal Damping Rubber Bearing Base Isolator
}

\author{
Daniel Noon \\ Brophy College Preparatory; 4701 North Central Avenue, Phoenix, AZ 85012 \\ Email: Dnoon20@brophybroncos.org
}

\section{ABSTRACT}

Today, increased tectonic plate activity in the Cascadia Megathrust Subduction Zone, located on the Pacific American Coast, has the potential to cause a massive earthquake with a magnitude upwards of 9.0 on the Richter scale and resulting tsunami that could cause severe architectural damage and large death tolls. Unfortunately, modern technologies used to reinforce buildings are not completely effective because they only absorb some shock in the foundation. Additionally, no current building design is completely resistant against the hydrostatic and buoyant forces from tsunamis. Therefore, it becomes necessary to design a cost-effective structure resistant to the effects of both of these natural disasters. After conducting a two year research in civil engineering and physics at the Arizona State University and Oregon State University, a hexagonal model with a two-part base isolation system was designed and built utilizing neoprene rubber, alloy steels, and shock-absorbers. The model was tested against an earthquake simulation of the 2011 Tohoku-Japan Earthquake and multiple direct shear tests, and against various computer-controlled waves to measure the model's stability against hydrodynamic forces of tsunamis. Both tests had the model remain stabilized, thus supporting the potential of life-size structures along global coastlines to provide a safe-shelter during natural disasters.

\section{Keywords}

Earthquake engineering; Tsunami protection; Direct shear testing; Wave generation; Base Isolation; Rubber bearings; Pyramidal; Hexagonal structure; Cascadia Subduction Zone

\section{Academic Disciplines}

Physics; Environmental Engineering

\section{INTRODUCTION}

One of the foremost issues in the international world is the fear of another natural catastrophe. Every month, high magnitude earthquakes occur around the world, causing extensive damage to property while taking hundreds of thousands of human lives. Occasionally, the seismic waves that create earthquakes will cause movement on the ocean floor that result in a tsunami. In fact, on March 11, 2011, a situation parallel to this scenario occurred in Tohoku, Japan which caused over 25,000 casualties and left 228,863 people homeless (Japan Earthquake \& Tsunami of 2011: Facts and Information). This past decade alone has been characterized by numerous earthquakes and tsunamis that have caused fatalities and extensive damage worldwide. This problem is even more pertinent today because approximately 3 billion people live just 100 kilometers from earthquake prone coastlines, thus making almost half the world's population at risk for becoming the victim of a deadly tsunami-earthquake (What Percentage of the World Population Lives near the Coast?). Even today, there is news of increased activity on the San Andreas Fault and major disaster could strike at any time. Now more than ever is there an urgency to minimize future fatalities and provide shelter to the millions of people living along the coastline during these impending catastrophes (The Earthquake That Will Devastate the Pacific Northwest).

Over the past 80 years, there have been numerous earthquakes and tsunamis that have claimed the lives of thousands of innocent people. Currently, there is no structure that effectively protects against the effects of both natural disasters, though such a structure is absolutely necessary because both an earthquake and tsunami are more likely to occur together in the same geographical region. With such a disaster, lack of resources and electricity, roadblocks, and overall panic can lead more people unable to evacuate efficiently. Additionally, there is evidence of increased activity on the San Andreas Fault in the Cascadia Megathrust Subduction Zone on the West Coast of the United States. This activity leads scientists to believe that within the next 30 years, an earthquake and tsunami of immense magnitude will occur, causing the loss of lives and damage from northwest Canada to Mexico (Unlocking the Cascadia Subduction Zone's Secrets: Peering into Recent Research and Findings). Thus, it is absolutely essential that a relief structure is created that can withstand a high magnitude earthquake and the aquatic forces of a tsunami in order to protect citizens from this predicted natural disaster as well as others that may occur in the future.

Currently, there are methods in place to minimize destruction from these natural disasters, such as precast concrete in the foundation of a building; however, no effective structures exist to provide a shelter that can protect people from both disasters simultaneously. As research in civil engineering shows thus far, in order for any building to be resistant to the terrestrial vibrations from seismic waves, the building must be framed with steel plate shear walls and incorporate a base isolation system that absorbs shock (How Earthquake-resistant Buildings Work). In doing so, the vibrations resist traveling up the shaft of the building, therefore preventing a structural collapse and other damage. Yet, the current models for base isolation systems are not infallible due to ineffective rubber bearings and alternating steel and rubber layering patterns within the base isolation system. In addition, civil architect Merrill W. Baird designed a seismically retrofitted 
building using his unique combined vibration control solution of a high damp rubber bearing as a foundation for a building to create an earthquake-resistant structure. His research showed the merits of rubber for shock absorption, which can be effective against earthquake damage (Municipal Services Building by Baird).

The first significant research measure taken to protect against tsunamis was orchestrated in 1960 following the Chilean earthquake that resulted in an unexpected tsunami. The method developed in order to protect Japanese citizens was to construct seawalls made of coastal dikes and concrete reaching heights of 6 meters. In regard to resisting damage caused by tsunamis, not much further research has been done. Instead, many more countries have created seawalls along their coasts to keep the waves away from the land. Though these are sometimes effective in smaller tsunamis, their main purpose is actually to prevent the erosion of the shoreline. Thus, there is no real protection against tsunamis of great magnitude, such as the one in Tohoku (Major Update: Catastrophic Failure of Seawalls in Japan).

This engineering project seeks to help the global community by designing a unique multipurpose, scaled earthquake and tsunami resistant structure to provide protection in times of natural disaster along the coastlines. This project was greatly influenced by the 2011 Tohoku tsunami-earthquake in Japan, because an incident of this magnitude is quite probable in the near future with the projected occurrence of "The Big One" tsunami-earthquake in the Cascadia subduction zone within the next 30 years. It was proposed that by using principles of architectural engineering, particularly concerning base isolation, and studying the destructive patterns of seismic waves, the most effective shelter structure would be hexagonally shaped with a unique two-part base isolation system. By making the structure hexagonal, there would be more triangular angles. Triangles have shown to be the strongest architectural shape because their angles resist collapse; therefore, in order for a triangular structure to collapse, the shape of it must change, which can only be accomplished by removing one of its edges (Building Strong Shapes with Triangles). As well, by incorporating two parts to the base isolation system, there is much more shock absorption, so there is significantly less of a likelihood for damage to result. Theoretically, such a prototype would also be able to withstand high magnitude earthquakes and tsunamis.

The model's success would be measured through testing its durability utilizing accelerometers to compare the displacement between the two-part hexagonal base isolation system and the top structure. Also this would be done through testing the prototype with computer generated tsunami waves to measure the structure's interaction to the hydrostatic and hydrodynamic powers, buoyancy, and additional forces from the waves. This would also support the potential for success of life-size structures along coastlines worldwide which can also provide shelter, food, water, medication, reduce panic, and provide an efficient mode of evacuation during times of need.

\section{FORCE CONCEPTS OUTLINE}

\subsection{Tsunamis Forces}

1.) Tsunami load should be less than the capacity the walls and columns can take. This force is definitely measurable in terms of whether or not the building survives the waves from tsunami tank.

2.) Hydrostatic Force- when a tsunami rises, so does the pressure of the base. This building prevents this force from affecting the panel side facing the tsunami (measureable with technology at O.H. Hinsdale Wave Laboratory).

3.) Shear force- The shearing of the building after the tsunami's initial impact should be resisted. Here, if the building does show some stable movement it will pass this section.

5.) Axial force of building should be less than its capacity. This meaning the force that is put on the center of the building should be less than the capacity of the building. This is true in our case.

6.) Hydrodynamic force- In a specific case, the water from the tsunami would not rise enough to completely cover the top of the building so there is somewhat of a vertical evacuation. The model should be able to withstand the drag that comes from this force as well. This is measurable through the technology at the O.H. Hinsdale Wave Lab.

7.) Surge- Our model should resist surge which is caused by a gush of water impacting on a structure. This force is very similar to the initial impact of the tsunami which will be able to be resisted.

\subsection{Earthquake Forces}

1.) Aftershocks- The structure should easily be able to resist smaller earthquakes after a large one.

-This force is measurable when the shake table slowly comes to a stop as well as it starting up. In this time frame, we will be able to see the difference of intensity in the shake table. This relates to aftershocks because they are smaller earthquakes that come after a large one which is represented by the startup and stopping of the shake table also shown in Illustration 2

2.) Tensional Stress- The building should combat the ground breaking apart and moving away from each other. Tensional stress as with any other kind of ground stress on the building should measure in the same way and should all be resisted.

3.) Compressional Stress- The building should combat the ground breaking apart and moving closer together.

Compressional stress as with any other kind of ground stress on the building should measure in the same way and should all be resisted.

4.) Shear stress- The building should combat the ground breaking apart and moving in opposite directions.

5.) Horizontal and stiff juts of the shaking ground would be resisted. This can be easily shown visually as the shake table starts and stops with stiff juts. 


\section{EXPERIMENTAL WORK AND MATERIALS}

To begin the process, the computer software SketchUp was used to design a virtual model of an effective prototype that would theoretically be resistant to the frequency of motion from an earthquake's seismic waves as well as the velocity of a resulting tsunami wave. After discussing the practicality of the finished structural design with consulting professors at universities, the process for finding the most appropriate materials began.

First, sheets of neoprene rubber of varying durometers were tested in regard to their respective hardness, strength, flexibility, traction, and weight. The different durometer values are based on the Shore scale, which also tests these variables. However, for the purpose of this research, it was necessary to test each characteristic independently in order to determine the best durometer of neoprene rubber to support the rubber's greatest resistance to indentation as well as shock-absorption upon impact during the earthquake and tsunami simulations. After examining the 30, 40, 50, 60 durometer rubber sheets, the 50 durometer neoprene rubber was used because it showed be a proportional model representation of the rubber that would be used in an actual structure. At a local rubber supplier, the 50 durometer neoprene rubber ( $1 / 4$ " thickness) was obtained and cut into hexagonal shapes.

The next component of the experimental design process was to determine which metal would be best to use to create the exterior of the prototype as well as the base isolation system. Steel was determined to be the material, due to its superior efficiency and cost-effectiveness as compared to other metals. However, it had to be determined whether mild steel or stainless steel was to be used for each component of the prototype, as both have different properties. We concluded that mild steel would rust more easily but still be much easier to weld, while the stainless steel would be much sturdier due to its resistance to corrosion and lack of malleability, which makes it stronger. Thus, based on these characteristics, it was determined that the stainless steel would be used for the top exterior structure and mild steel for both parts of the base isolation system including the square sheets added to the top and bottom of the base isolation system. The mild steel and stainless steel sheets were then obtained in different thickness, 1/8" (for top structure) and $1 / 16$ " (for base isolation system) from a local metal supplier.

After obtaining the rubber and steel sheets, these materials were cut by a waterjet machine, with the assistance of employees of the facility, into hexagonal shapes for the base and top structure, into triangles for the inner pyramid of the prototype, and into squares for the exterior walls and top and bottom sheets enclosing the base isolation system to separate it from the top structure. For the walls of structure, six 1' by 1' stainless steel squares were cut and two 2' by 2 ' mild steel squares were cut for the top and bottom sheets enclosing the base isolation system. For the inner pyramid, six 1 ' by 16.97 " by 16.97 " stainless steel triangles were cut. This inner pyramid would be used to strengthen the weak points of the hexagonal shape. For the top structure, two hexagons with side lengths of 1 ' were cut from stainless steel. All of these cutouts were 1/8" thick. With the assistance of employees at a welding company, these cut sheets were welded together to form a hexagonal structure that contained an inner pyramid for added stability. Additionally, the welding of the metal, as opposed to simply using bolts, ensured that the structure would be entirely waterproof.

After creating the top structure, the two-part base isolation system was created. First, thirteen stainless steel sheets and twelve 50 durometer neoprene rubber sheets were cut into hexagons with side lengths of 1 ' that then had hexagons with side lengths of 4" cut in the center to create the layers for the laminated rubber bearing component. These 4 " hexagon sheets for both steel and rubber were then cut further into hexagons of 3" side lengths for the layers of the high damping (elastomeric) rubber bearing. Each sheet of steel and rubber was then coated with one layer of the Chemlok 205 Primer. Then, they were coated with 3M 90 Spray and immediately stacked into twenty-five layers of alternating stainless steel and neoprene rubber to create the base, beginning with the stainless steel on the bottom. The larger hexagon would serve as the exterior of the base isolation system, the laminated rubber bearing, while the smaller hexagon, the high damping rubber bearing, would be placed in the cutout hole within the laminated rubber bearing and be surrounded by six shock absorber units.

The shock absorber units were created out of one 1/32" mild steel sheet attached to four plastic shock absorbers with gorilla glue. After creating six shock absorbers and waiting until the adhesives on the base had cured, the shock absorbers were placed between the two bearings that comprised the base isolation system on each hexagonal side. Lastly, the two 1/8" thick square mild steel sheets were added to the top and bottom of the base isolation system. All parts of the model were then secured with washers, nuts, and bolts of $3 / 8$ " diameter and varying lengths to secure our top structure to the base.

After creating a complete prototype, the model was tested to compare the it against a previously developed simulation of the 2011 Japanese tsunami-earthquake by attaching accelerometers to the bottom of the base isolation system and the top structure to compare the motion of these two parts in gravitational-force (g). Additionally, the model was tested against computer-controlled waves programmed to interchange velocity, acceleration, and force at the wave research laboratory.

\section{TESTING PROCESS AND RESULTS}

\subsection{Direct Shear Test \& Discussion}

The direct shearing machine was programmed to push the model at a constant repeated motion to test the base isolation concept before earthquake test. The frequency used in the test is $20 \mathrm{~Hz}$ and the amplitude of the wave is $1 \mathrm{~mm}$. That is also because of the limitation of the test equipment. That represents the real frequency of $20 / 50=0.4 \mathrm{~Hz}$ so the corresponding period is $1 / 0.4 \mathrm{~Hz}=2.5 \mathrm{~s}$. Since the Structure usually is a long-period response, the period of the structure usually is around 3s-5s. The Sine Wave Graph (4.12 Graph 1) shows that base isolation system shaking between 0.2 to 
$0.3 \mathrm{~g}$ more than the top structure. If this resulted in 0 to $0.2 \mathrm{~g}$ range, then the top structure would shake more and the isolation system would render useless. On the other hand, it there was too much of a difference $(0.3 \mathrm{~g}$ and above), then it would shake too quickly also defeating the purpose of the system by causing too much disturbance. Therefore, this direct shear test supports the hypothesis that a two-part base isolation system consisting of alternating alloy steel and 50 durometer neoprene rubber sheets separated by shock absorbers can resist model earthquake forces from its ability to resist the seismic wave vibrations.

\subsection{Graph 1.}

\section{Acceleration Response}

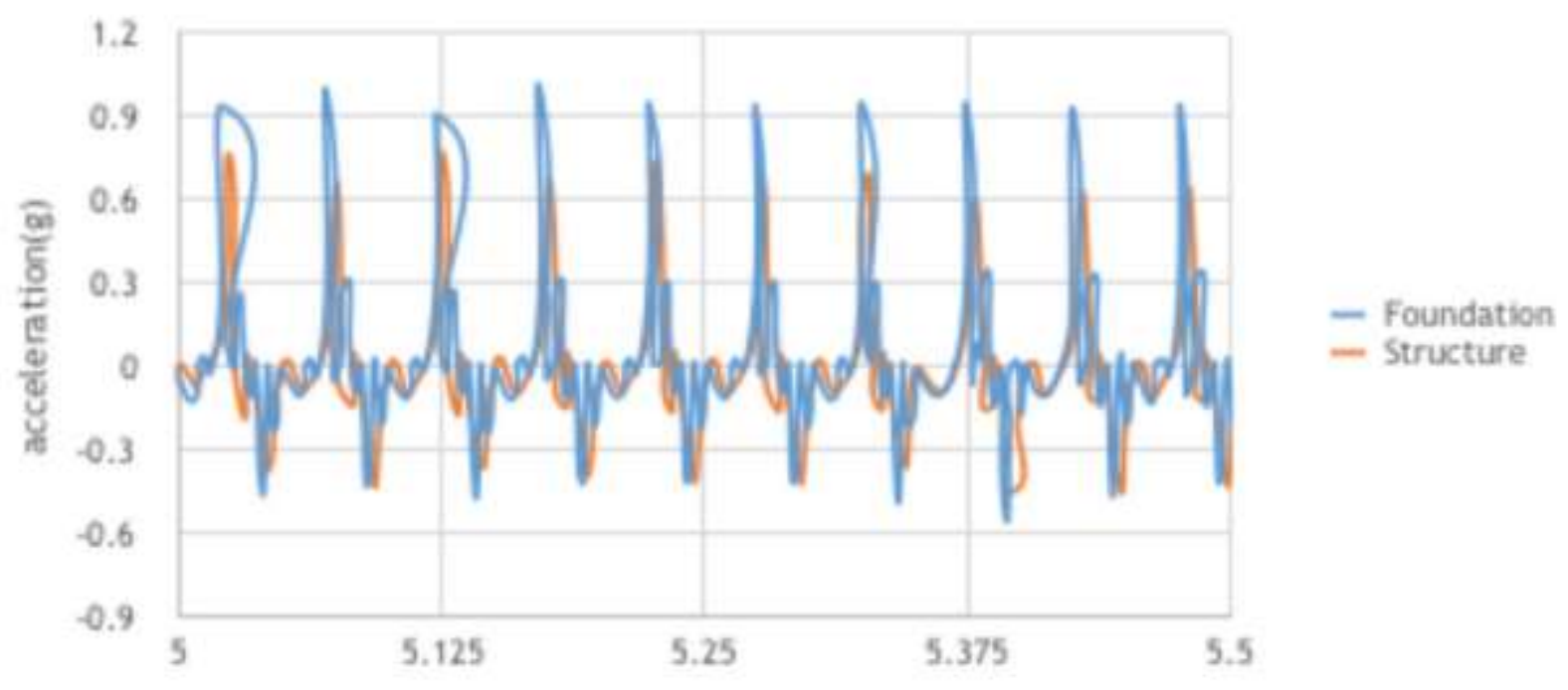

\subsection{Tohoku 2011 Earthquake Simulation \& Discussion}

This earthquake test is an accurate simulation of the 2011 Tohoku Earthquake scaled down 50 times for the purpose of this prototype experimentation. The input earthquake has a real time duration of 300s, so in the test machine, it will be $300 / 50=6 \mathrm{~s}$. The graph only displays 4 seconds of the motion because for the first 2 seconds, the acceleration sensor cannot record the real response, so the response of the two sensors in the first 2 seconds was removed, so was the earthquake. Because of the limitation of test machine, the expected maximum displacement of the machine should be $35 \mathrm{~mm}$, the real maximum displacement used in the test is $25 \mathrm{~mm}$. The input earthquake motion is M9 and th PGA of the motion is $1 \mathrm{~g} \mathrm{(4.22} \mathrm{Graph} \mathrm{1)} \mathrm{It} \mathrm{has} \mathrm{been} \mathrm{modified} \mathrm{by} \mathrm{baseline} \mathrm{correction} \mathrm{and} \mathrm{frequency} \mathrm{filtering} \mathrm{so} \mathrm{the} \mathrm{motion} \mathrm{can} \mathrm{be} \mathrm{used}$ Two accelerometers were attached to the top structure and the base isolation system to determine the difference in displacement of the two. The force of aftershocks is shown through the lower forces of the earthquake tests on the graph (in graphs below). Additionally, the horizontal and stiff juts on the base show resistance to the hardest shake at 1.5 seconds on this Earthquake Response graph. The red line in this graph represents the movement of the top structure and the black line in graph represents the movement of the base isolation system. Because the black portion of the sine graph is higher at every point as compared to the red sine graph (an average from .5 to $1 \mathrm{~g}$ ), it can be concluded that the base is moving at a steady rate and partially isolating the shocks from being transferred to top structure, thus creating a great amount of stability. Furthermore, because the model resisted the shocks of the most powerful shakes, it can be concluded that all of the aftershocks would be resisted.

\subsection{Graph 1.}




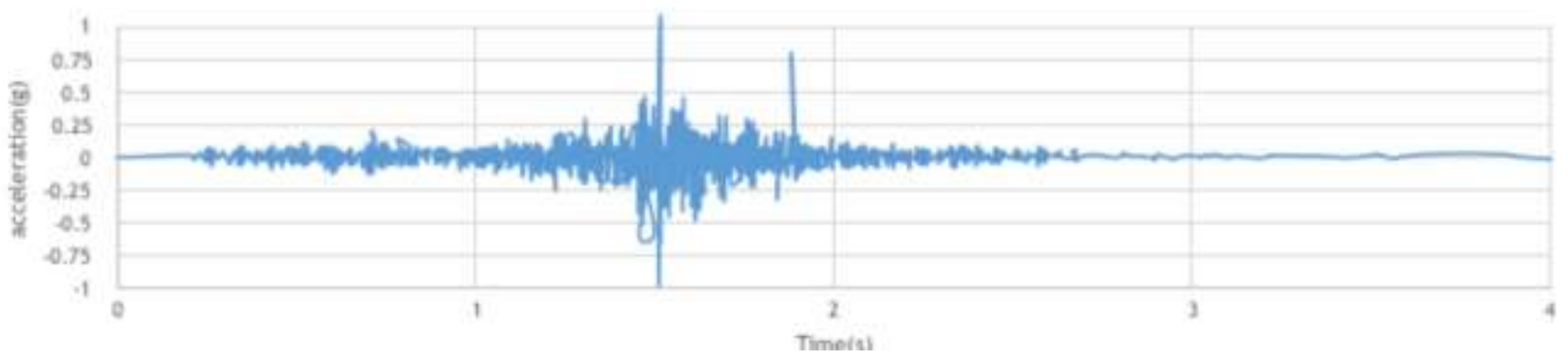

\subsection{Graph 2.}

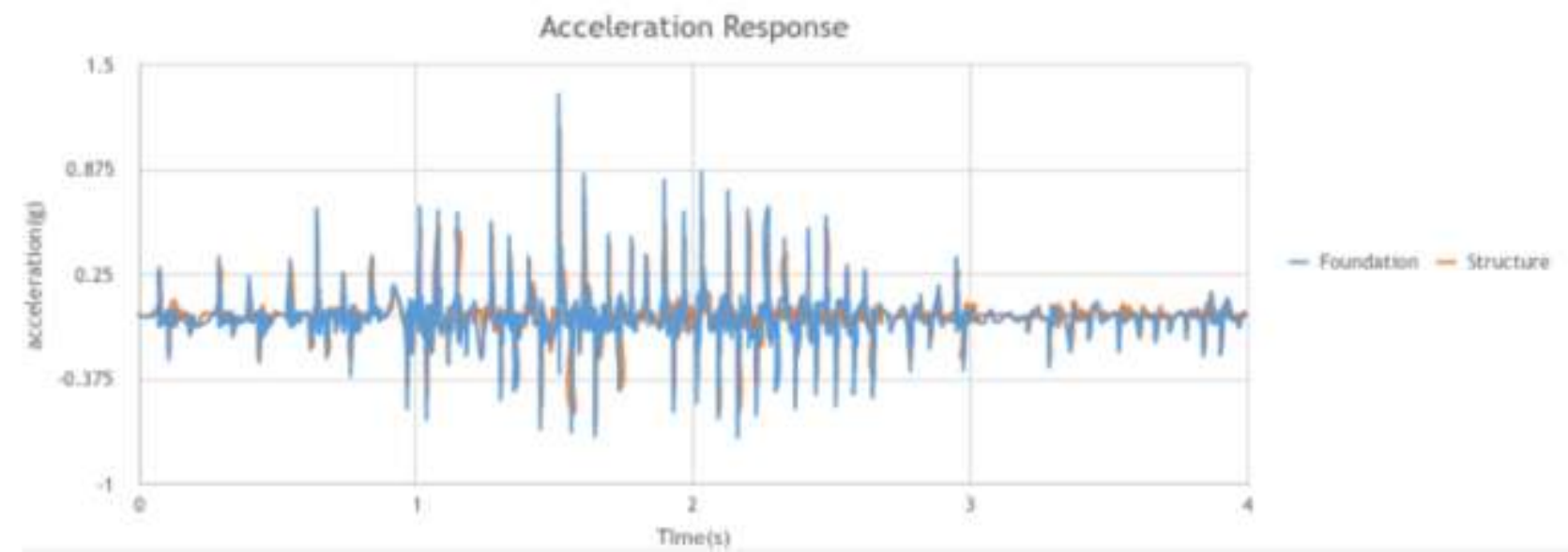

\subsection{Tsunami Basin Wave Simulations \& Discussion}

For the tsunami basin test, 17 tests measuring the effect of different lengths from the shoreline, different configurations (such as panel side or angle side facing the wave), and different heights of waves on tsunami-force resistance were performed. The velocity was another element observed throughout experimentation; however, it was not able to be manipulated individually as it depends on heights of waves. The purpose of this experiment was to determine whether panel-side or angle side configuration would be more effective against tsunami waves, as well as whether the structure of the prototype would be waterproof and resistant to indentation upon impact. The scaling used was $1 \mathrm{~cm}$ : $5 \mathrm{ft}$, as this made the most sense in regard to the scaling of the physical model.

The heights of the waves were scaled from $5-50 \mathrm{~cm}(15-150 \mathrm{ft}$ in real life). Three distances from the shoreline were tested $(83,166$ and $249 \mathrm{~cm})$ to see how each would affect the movement on the building. $83 \mathrm{~cm}$ was the closest possible distance from the shoreline for this test. This length also ensures that the forces put on the prototype from the waves (hydrostatic, axial, shear, hydrodynamic, and surge forces) are able to be measured.

The first set of tests were conducted with the prototype located $83 \mathrm{~cm}(322 \mathrm{ft})$ from the shoreline facing the wave as a panel side. At wave heights of $5 \mathrm{~cm}(15 \mathrm{ft}), 10 \mathrm{~cm}(30 \mathrm{ft})$, and $20 \mathrm{~cm}(60 \mathrm{ft})$, the model did not move. At a wave height of $30 \mathrm{~cm}(90 \mathrm{ft})$, the model moved $13 \mathrm{~cm}(39 \mathrm{ft})$. At a wave height of $40 \mathrm{~cm}(120 \mathrm{ft})$, the model moved $51 \mathrm{~cm}(153 \mathrm{ft})$. At a wave height of $50 \mathrm{~cm}(150 \mathrm{ft})$, the model moved $88 \mathrm{~cm}(264 \mathrm{ft})$.

The next set of tests was conducted with the model located $83 \mathrm{~cm}(322 \mathrm{ft})$ from the shoreline facing the wave angle side. The tests conducted at wave heights of $5 \mathrm{~cm}(15 \mathrm{ft}), 10 \mathrm{~cm}(30 \mathrm{ft})$, and $20 \mathrm{~cm}(60 \mathrm{ft})$ did not move the model. At a wave height of $30 \mathrm{~cm}(90 \mathrm{ft})$, the model moved $20 \mathrm{~cm}(60 \mathrm{ft})$. At a wave height of $40 \mathrm{~cm}(120 \mathrm{ft})$, the model moved $62 \mathrm{~cm}$ $(186 \mathrm{ft})$. At a wave height of $50 \mathrm{~cm}(150 \mathrm{ft})$, the model moved $110 \mathrm{~cm}(330 \mathrm{ft})$.

The next tests were conducted at $166 \mathrm{~cm}$ from the shoreline (2x the distance of the previous set of tests) at a panel-facing configuration. The first test was done at a wave height of $30 \mathrm{~cm}(90 \mathrm{ft})$ and the model did not move. At a wave height of $40 \mathrm{~cm}(120 \mathrm{ft})$, the model moved $7 \mathrm{~cm}(21 \mathrm{ft})$. At a wave height of $50 \mathrm{~cm}(150 \mathrm{ft})$, the model moved $55 \mathrm{~cm}(165 \mathrm{ft})$.

The last set of tests was conducted at $249 \mathrm{~cm}$ from the shoreline (3x the distance of the original set of tests) at a panel-facing configuration. At a wave height of $30 \mathrm{~cm}(90 \mathrm{ft})$, the model did not move. At a wave height of $40 \mathrm{~cm}$, the model moved $4.5 \mathrm{~cm}(13.5 \mathrm{ft})$. At a wave height of $50 \mathrm{~cm}(150 \mathrm{ft})$, the model moved $17 \mathrm{~cm}(51 \mathrm{ft})$.

Though the model moved significant distances, this was expected because of the lack of friction on the concrete where the model was placed during testing, as well as because the model was not secured to the floor as would be the case in real life. Additionally, in every test, there was no damage to the exterior of the structure, nor was water leakage. 
Thus, this model is successfully waterproof and resistant to exterior damage from tsunamis of even extremely high velocities resulting from rare mega-tsunamis of wave heights beginning at $80 \mathrm{ft}$.

Throughout this series of tests, there was a pattern indicating that the further away the model was from the shoreline, the less it moved. This is reasonable considering the fact that the acceleration, and therefore force, of the tsunami decreases with time, and time increases as the distance increases. Also, it was seen that the panel side of the structure better resisted the force of the varying waves. After checking the base, it was seen that it absorbed only a small amount of water (as a large influx of water can result in damage to the base isolation system) was absorbed, thus supporting the notion that this structure can be used as a model to protect against catastrophic tsunami-earthquakes that are very likely to occur in our near future.

\section{SCIENIFIC IMPLICATIONS AND CONCLUSION}

Though in the past, innovations have been made in making individual buildings more resistant to the forces of earthquakes, such as using steel in the foundation or adding rubber bearings to the base, and the use of steel and rubber in alternating layers to create a more stable foundation that absorbs shock more readily. Additionally, this prototype is different in that there are two parts to the base isolation system - the laminated rubber bearing and the high damping rubber bearing that are separated by plastic shock absorbers. This design facilitates for the most effective shockabsorption so that the top structure of the building, which is being used for sheltering purposes to save people, is unaffected by seismic vibrations.

In regard to tsunamis, not much has been done in making buildings more resistant to waves besides waterproofing. Instead, preventative measures like building seawalls and evacuation have been taken to save lives in the case of such an event. This prototype through this experimentation has shown significant resistance to indentation, thus keeping the building intact. Of course, the data shows that the building did move with high-velocity waves; however, it can be assumed that with a life-size model, this would not happen because the structure would be further secured to the foundation, as modern buildings are.

\section{FIGURES/CAPTIONS}

\subsection{Sketchup Figures/Captions}

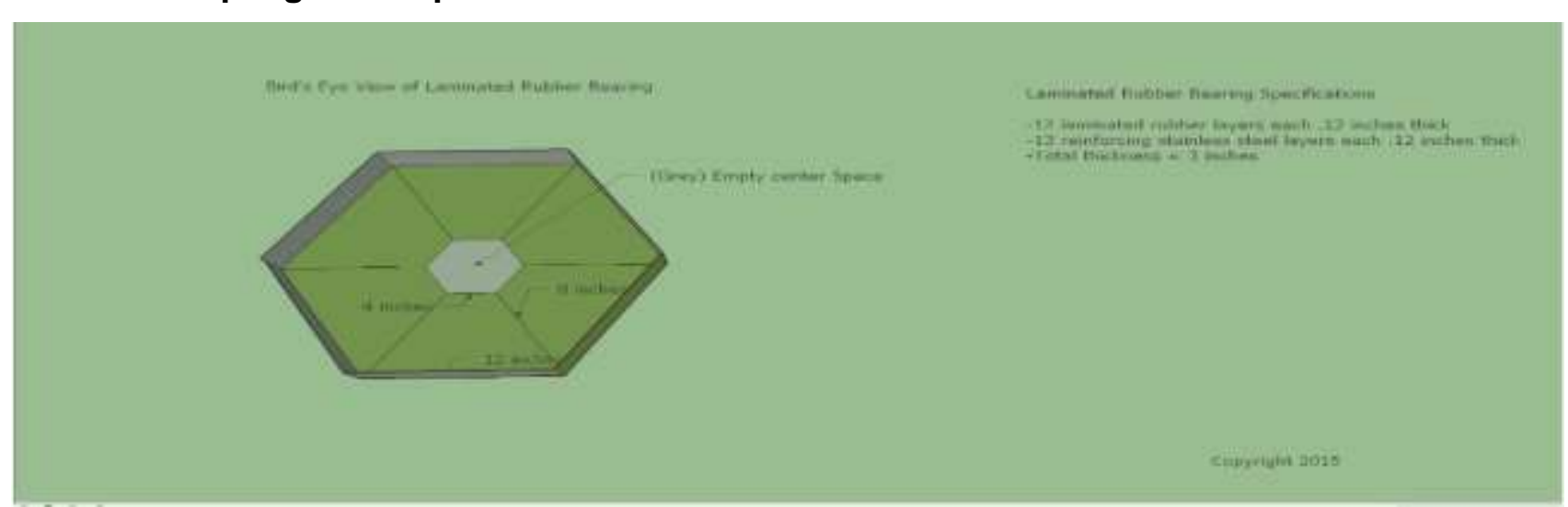

Figure 1: Specifications of Lamnated Rubber Bearing (LRB) 
1. Made up of 25 firers ( 12 high damping rubber and 13 wainiess steet)

2 Toes thickeses $=3$ inches

2. Fach herapanal side $=2.11$ inches

4. Eact nutber laver $=.12$ inelves thick

S. Esch steel lever $=.12$ inches thick

Figure 2: Specifications of High Damping Rubber Bearing (HDRB)

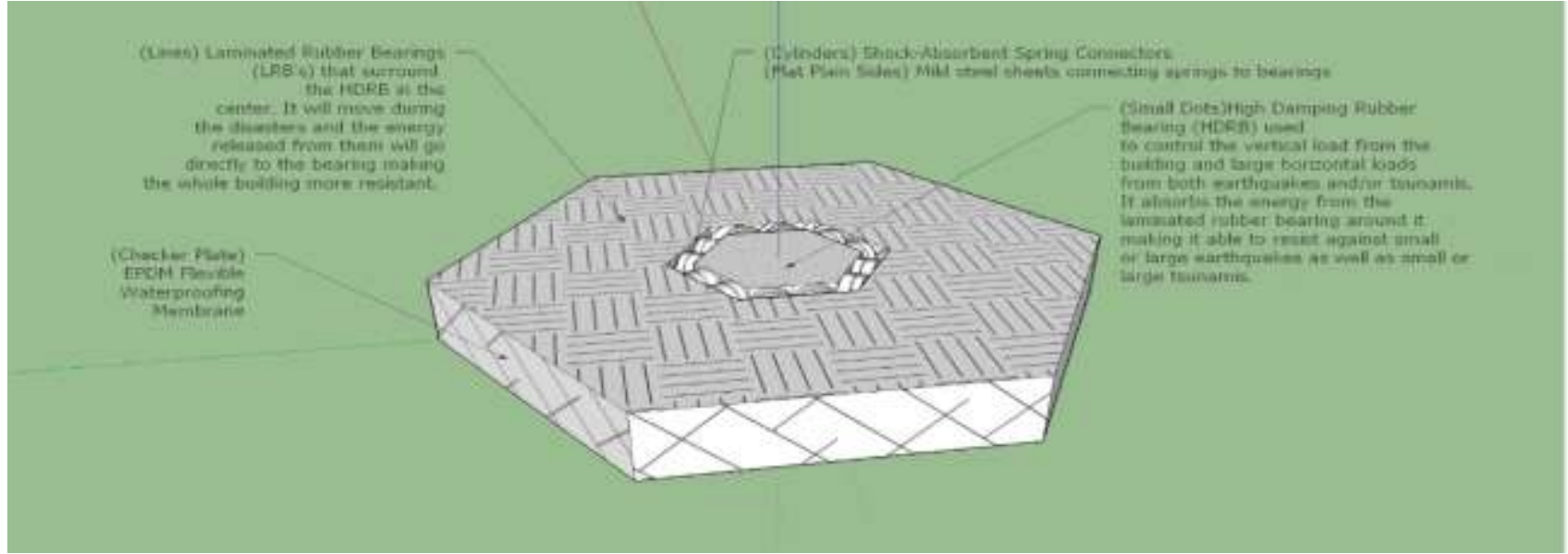

Figure 3: Labeled Parts of Base Isolation System 


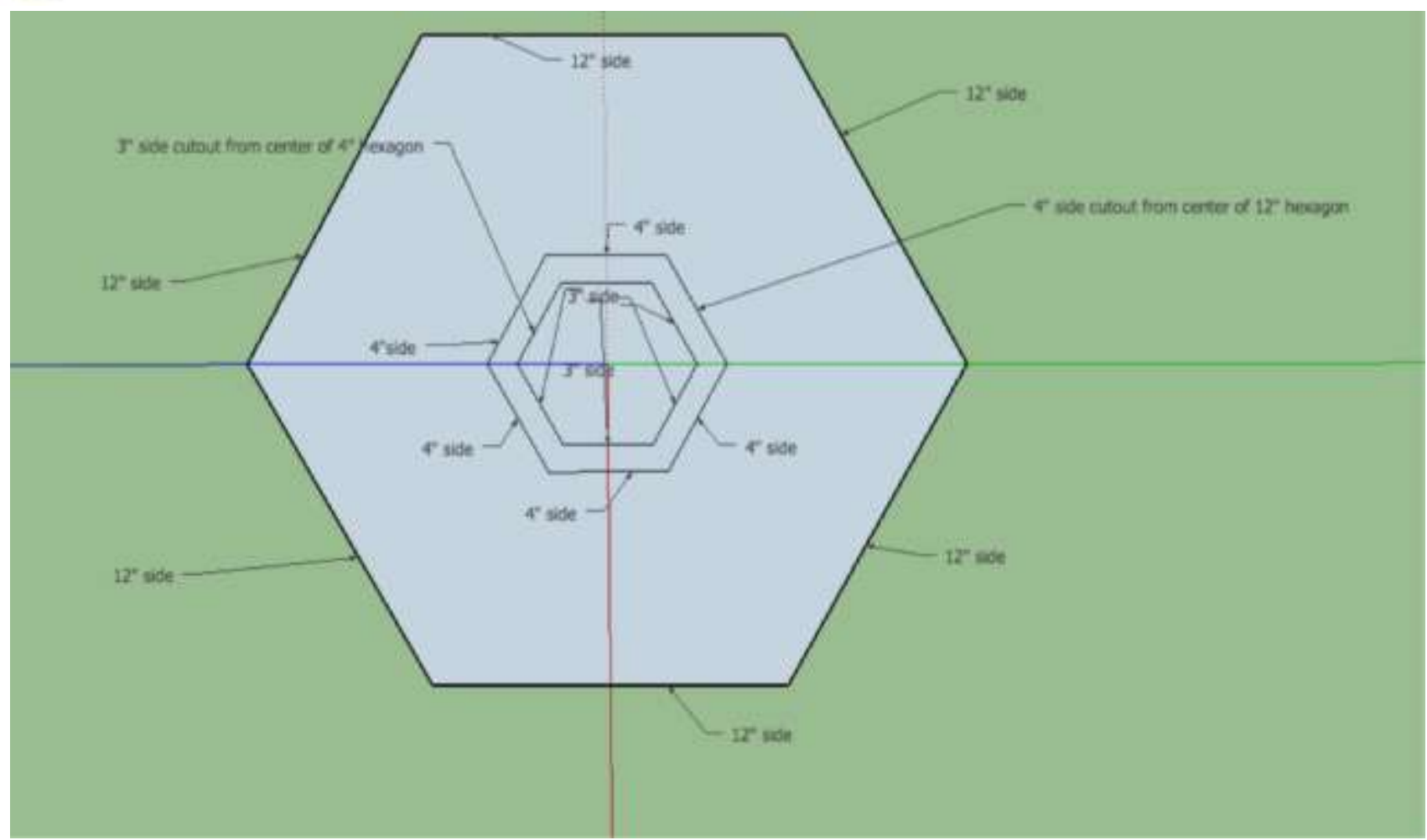

Figure 4: Dimensions of Base Isolation System

\subsection{Misc. Structural Figures/Captions}

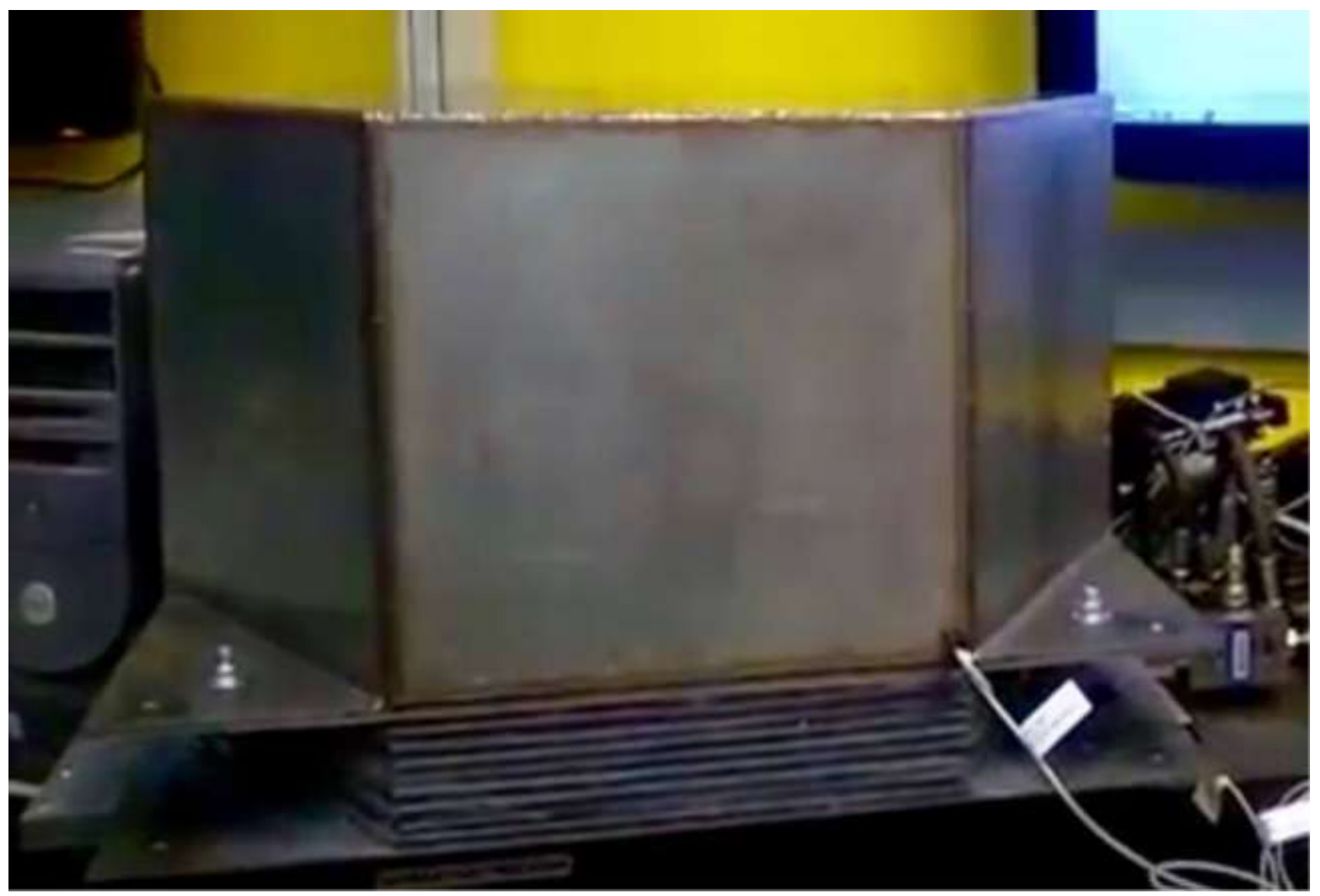

Figure 1: Full Structure under Earthquake/Direct Shear Tests 


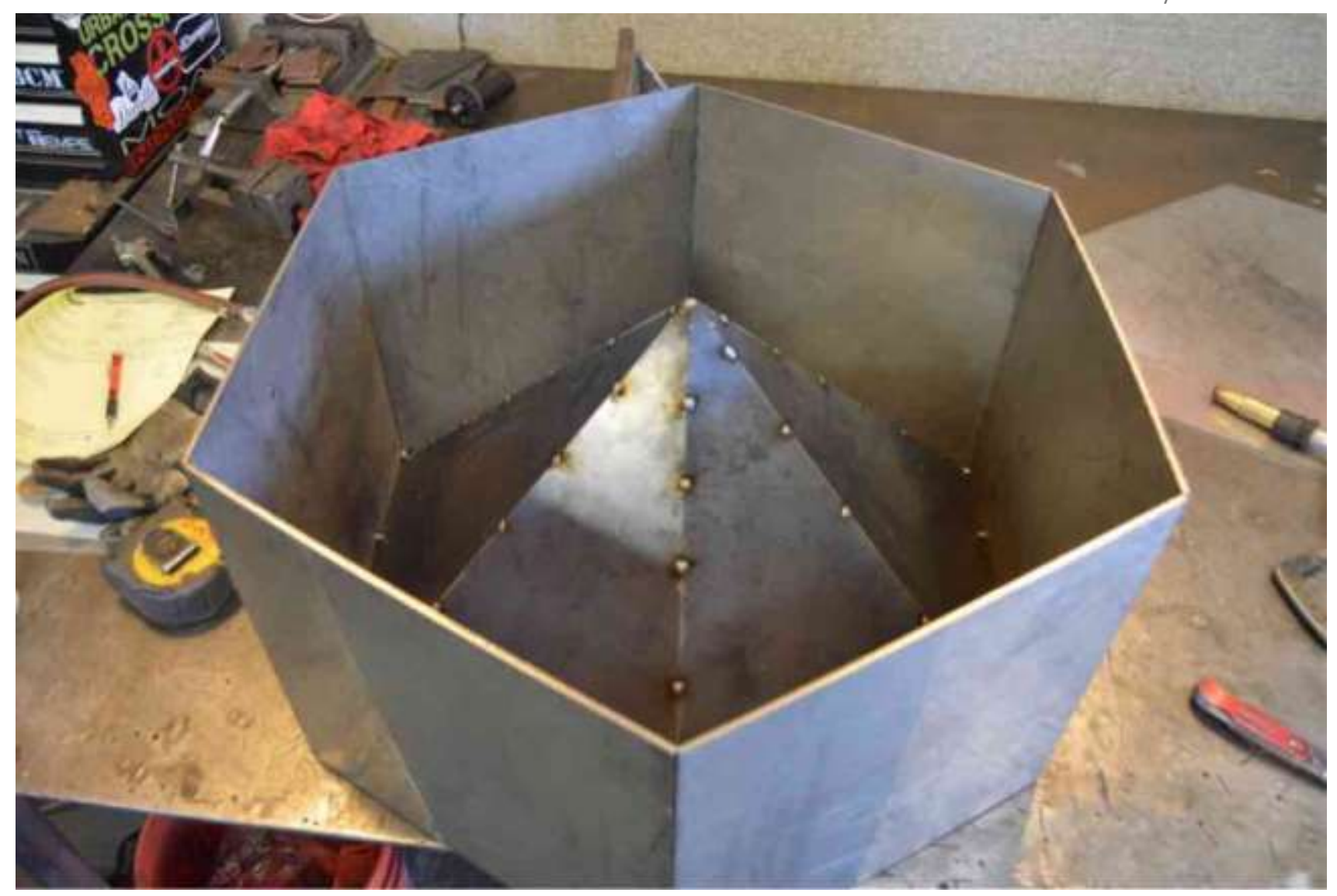

Figure 2: Inner Pyramidal Structure

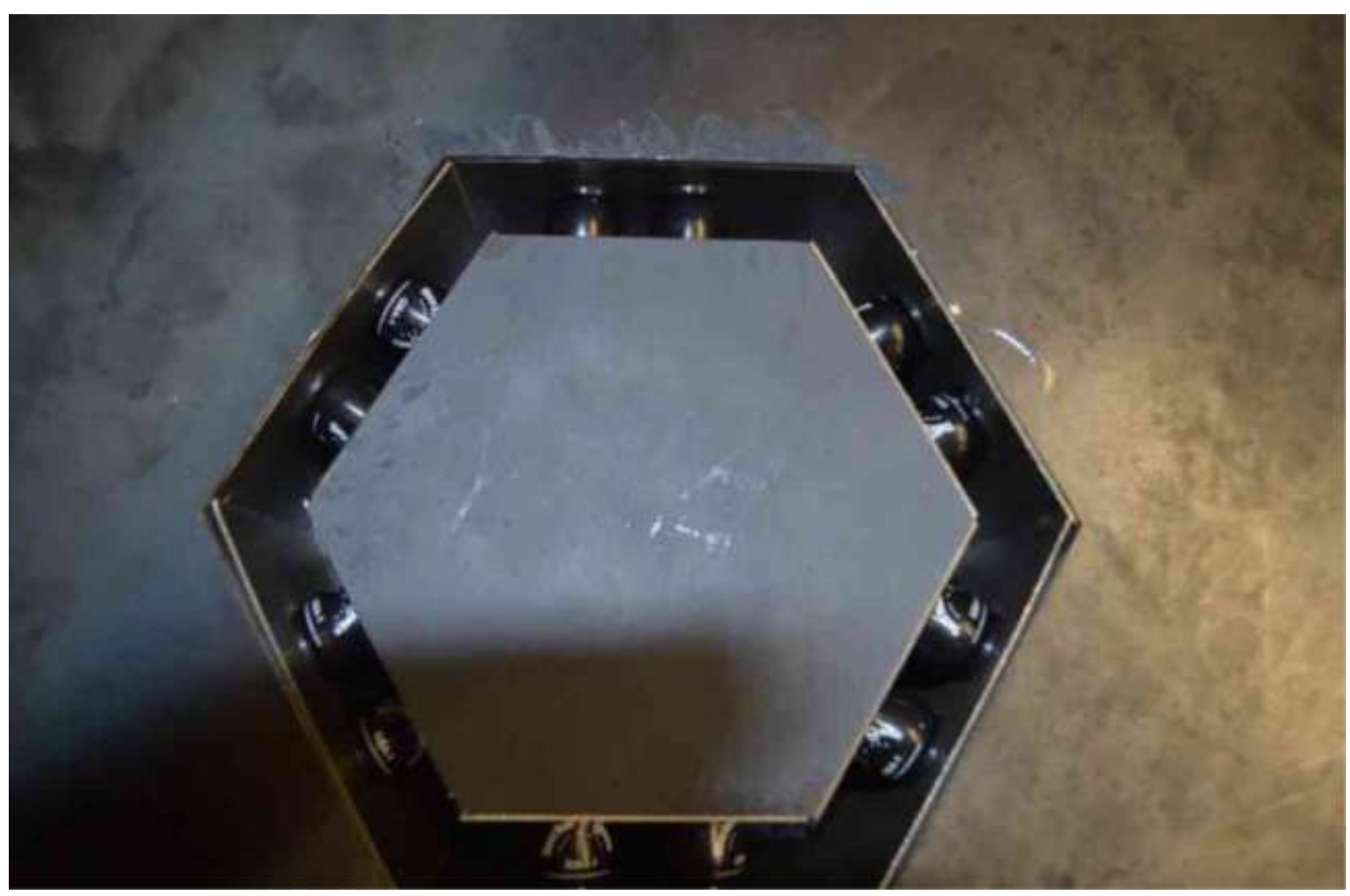

Figure 3: Shows Shock Absorbers Between LRB and HDRB 


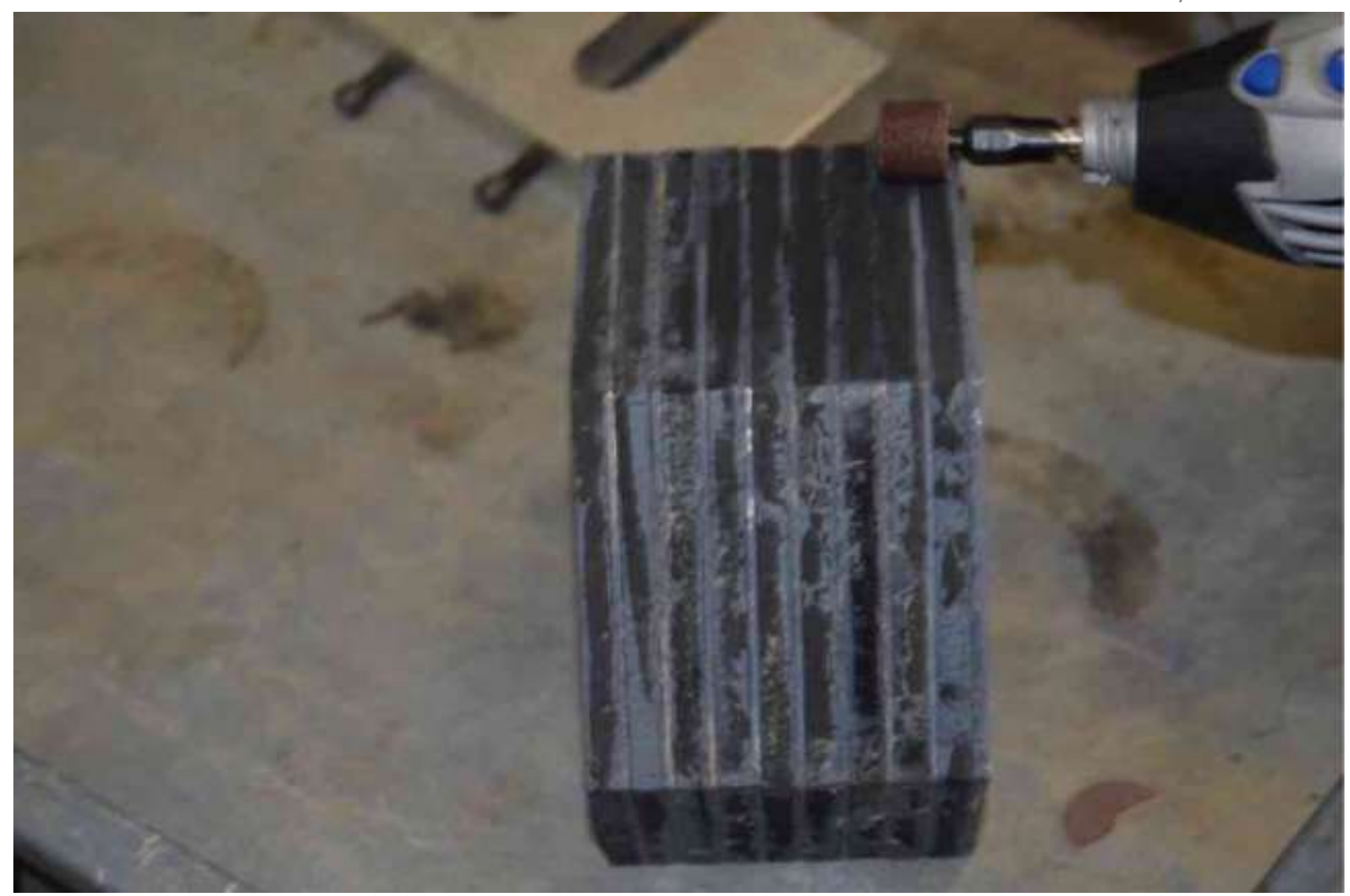

Figure 4: Inner High Damping Rubber Bearing Layers

\section{ACKNOWLEDGMENTS}

1. Dr. Pedro Lomonaco

Email: pedro.lomonaco@oregonstate.edu)

Director of the O.H. Hinsdale Wave Laboratory at OSU Office

Civil \& Construction Engineering

Phone: 541-737-2875

2. Dr. Edward Kavazanjian

Email: edward.kavazanjian@asu.edu

Arizona State University Professor of Civil Engineering

School of Sustainable Engineering and the Built Environment

Department of Civil and Environmental Engineering

Ira A. Fulton School of Engineering

Phone: (480)727-8566

3. Dr. Keith Hjelmstad

Email: Keith.Hjelmstad@asu.edu

Arizona State University Professor

School of Sustainable Engineering and the Built Environment

Phone: (480)316-5988

\section{COMPANIES INFORMATION}

1.) CMA Waterjet, LLC; 3102 S Roosevelt St Tempe, AZ 85282; (480) 966-9538

2.). Liquid Metal Concepts, LLC; 3031 S 46th St, Phoenix, AZ 85040: (480) 967-2677 
3.) McMaster-Carr Supply Company; (404) 346-7000

4.) Aaa-Acme Rubber Co.; 2003 E 5th St, Tempe, AZ 85281; (480) 966-9311

\section{REFERENCES}

1. "The 10 Most Destructive Tsunamis in History." Australian Geographic. Web. 15 Feb. 2016.

2. "About TCP." About TCP. Web. 15 Feb. 2016. <http://tsunamiportal.nacse.org/pages/portal.force.page.php>.

3. "Base Isolation: Origins and Development." Base Isolation: Origins and Development. Web. 15

Feb. 2016.

4. "Building Strong Shapes with Triangles." Building Strong Shapes with Triangles. Web. 15 Feb. 2016.

5. "Cascadia Subduction Zone | Pacific Northwest Seismic Network." Pacific Northwest Seismic Network. Web. 15 Feb. 2016.

6. "Del Norte Triplicate." Del Norte Triplicate. Web. 15 Feb. 2016. <http://www.triplicate.com/Northcoast-Life/NorthcoastLife/Cascadia-Quake-Our-Big-One>.

7. "Earthquake Scenarios." Earthquake Scenarios. Web. 15 Feb. 2016. <http://www.crew.org/productsprograms/earthquake-scenarios>.

8. "Guidelines for Design of Structures for Vertical Evacuation from Tsunamis." Guidelines for Design of Structures for Vertical Evacuation from Tsunamis | FEMA.gov. N.p., n.d. Web. 02 Mar. 2017.

9. "The Earthquake That Will Devastate the Pacific Northwest." The New Yorker. Web. 15 Feb. 2016. F. Hydrodynamic Forces. Clarkson University. Web. <http://web2.clarkson.edu/projectsfluidflow/courses/me537/1_2Drag.pdf>.

10. "How Do Base Isolators Work?" Science Learning Hub RSS. Web. 15 Feb. 2016.

11. "How Earthquake-resistant Buildings Work." HowStuffWorks. HowStuffWorks.com, n.d. Web. 15 Feb. 2016.

12. "Illumin - Base Isolation." Illumin - Base Isolation. Web. 15 Feb. 2016.

13. "Japan Earthquake \& Tsunami of 2011: Facts and Information." LiveScience. TechMedia Network, Web. 15 Feb. 2016.

14. "Major Update: Catastrophic Failure of Sea Walls in Japan." Daily Kos. Web. 1 Feb. 2016.

15. "Mega-quake: The 'big One' Could Happen Soon, but Probably Not Where You Think." MNN. Web. 15 Feb. 2016.

16. "Municipal Services Building by Baird." CIVIC. 6. Web. 15 Feb. 2016.

17. Oskin, By Becky. "What Is a Subduction Zone?" LiveScience. TechMedia Network, 06 May 2015. Web. 15 Feb. 2016.

18. "Richter Scale." \& Magnitude. Web. 15 Feb. 2016.

19. Survival Building. Tsunami Load Determination for On-Shore Structures. Web. <http://www.fzk.unihannover.de/fileadmin/institut/Veranstaltungen/DFG-RT/DFG-pdf/1.2.1_-_Yeh_Harry_-_DFGTsunamiForce.pdf>.

20. "Tsunamis." Tsunamis. Web. 15 Feb. 2016. <http://www.ussartf.org/tsunamis.htm>.

21. "What Percentage of the American Population Lives near the Coast?" US Department of Commerce, National Oceanic and Atmospheric Administration. Web. 18 Sept. 2016.

22. "Unlocking the Cascadia Subduction Zone's Secrets: Peering into Recent Research and Findings." Unlocking the Cascadia Subduction Zone's Secrets: Peering into Recent Research and Findings. Web. 15 Feb. 2016

\section{Author's biography}

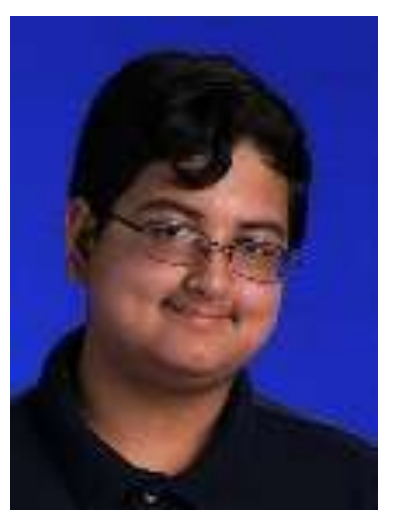

Student Researcher Mr. Daniel Noon at Brophy College Preparatory in Arizona. His field of interest is in environmental engineering and physics. Student Researcher Mr. Daniel Noon at Brophy College Preparatory. 